\title{
Deep sea explosive eruptions may be not so different from subaerial eruptions
}

Gianluca Iezzi ${ }^{1,2, *}$, Gabriele Lanzafame ${ }^{3,4}$, Lucia

Mancini ${ }^{4}$, Harald Behrens ${ }^{5}$, Stella

Tamburrino $^{6}$, Mattia Vallefuoco ${ }^{6}$, Salvatore

Passaro $^{6}$, Patrizio Signanini ${ }^{1}$ and Guido Ventura ${ }^{2}$

${ }^{1 *}$ Department of Engineering and Geology, G. D'Annunzio

University, Chieti, Italy ( ${ }^{*}$ correspondance:

gianluca.iezzi@unich.it)

${ }^{2}$ National Institute of Geophysics and Volcanology, Rome, Italy

${ }^{3}$ Department of Biological, Geological and Environmental Sciences, University of Catania, Catania, Italy

${ }^{4}$ Elettra-Sincrotrone Trieste S.C.p.A., Basovizza, Trieste, Italy

${ }^{5}$ Institute for Mineralogy, Leibniz University, Hannover, Germany

${ }^{6}$ Institute of Marine Sciences (ISMAR-CNR), Napoli, Italy ${ }^{4}$ Elettra-

The dynamics of deep sea explosive eruptions, the dispersion of the pyroclasts, and how submarine eruptions differ from the subaerial ones are still poorly known due to the limited access to sea environments. Here, we analyze two ash layers representative of the proximal and distal deposits of two submarine eruptions from a 500 to $800 \mathrm{~m}$ deep cones of the Marsili Seamount (Italy). Fall deposits occur at a distance of more than $1.5 \mathrm{~km}$ from the vent, while volcanoclastic flows are close to the flanks of the cone. Ash shows textures indicative of poor magmawater interaction and a gas-rich environment. X-ray microtomography data on ash morphology and bubbles, along with gas solubility and ash dispersion models suggest 200-400 $\mathrm{m}$ high eruptive columns and a sea current velocity $<5 \mathrm{~cm} / \mathrm{s}$. In deep sea environments, Strombolian-like eruptions are similar to the subaerial ones provided that a gas cloud occurs around the vent.

Iezzi, G., Lanzafame, G., Mancini, L. et al. Deep sea explosive eruptions may be not so different from subaerial eruptions. Sci Rep 10, 6709 (2020). https://doi.org/10.1038/s41598-020-63737-7 